\title{
LandAware: a new international network on landslide early warning systems
}

\author{
Calvello $M^{1}$, Devoli $G^{2}$, Freeborough $K^{3}$, Gariano $S L^{4}$, Guzzetti $F^{5}$, Kirschbaum $D^{6}$, Nakaya $H^{7}$, Robbins $J^{8}$, \\ Stähli $M^{9}$ \\ 1 University of Salerno, Italy \\ ${ }^{2}$ Norwegian Water Resources and Energy Directorate, Norway \\ ${ }^{3}$ British Geological Survey, United Kingdom \\ ${ }^{4}$ Research Institute for Geo-Hydrological Protection of the Italian National Research Council, Italy \\ ${ }^{5}$ National Civil Protection Department, Italy \\ ${ }^{6}$ National Aeronautics and Space Administration, United States of America \\ ${ }^{7}$ Ministry of Land, Infrastructure, Transport and Tourism, Japan \\ ${ }^{8}$ Met Office, United Kingdom \\ ${ }^{9}$ Swiss Federal Institute for Forest, Snow and Landscape Research, Switzerland
}

\section{Background}

Early Warning Systems (EWS) are important non-structural mitigation measures designed and used to avoid and/or minimize the impact posed by hazards on humans. They are often a cost-effective mitigation measure to adopt, and sometimes they are the only suitable option to manage the risk posed by natural hazards (Glade and Nadim 2008). UNISDR (2009) defines EWSs as a "set of capacities needed to generate and disseminate timely and meaningful warning information to enable individuals, communities and organizations threatened by a hazard to act appropriately and in sufficient time to reduce the possibility of harm or loss". A Landslide Early Warning System (LEWS) is specifically designed to monitor, forecast, and analyze conditions that could trigger one or more landslides, at a scale (local, regional, national, global) defined by system managers. The aim is, as for any EWS, saving human lives by issuing timely warnings and/or initiating other appropriate landslide risk mitigation actions. The design, implementation, management, and validation of LEWSs are topics that are drawing increasing attention in the scientific and technical literature (e.g. Intrieri et al. 2013, Stähli et al. 2015, Fathani et al. 2016, Sättele et al. 2016, Calvello 2017, Piciullo et al. 2018, Pecoraro et al. 2019, Guzzetti et al. 2020), highlighting several theoretical and practical complexities.

Many recent international initiatives have been highlighting the importance of EWSs for disaster risk reduction purposes. The European Climate Adaptation Platform (http://climate-adapt.eea.europa.eu/) states "Early warning systems can enhance the preparedness of decision-makers and private individuals for climate-related natural hazards and their readiness to harness favourable weather conditions." Goal no. 13 "Take urgent action to combat climate change and its impacts" of UN Agenda 2030 for sustainable development (http://sustainabledevelopment.un.org/post2015/transformingourworld) includes "Improve education, awareness-raising and human and institutional capacity on climate change mitigation, adaptation, impact reduction and early warning". One of the seven global targets of the Sendai Framework for Disaster Risk Reduction 2015-2030 (UNISDR 2015) is "substantially increase the availability of and access to multihazard early warning systems and disaster risk information and assessments to the people by 2030". Concerning landslides, the important role played by LEWSs has been highlighted by the ISDR-ICL Sendai Partnership 2015-2025 (https://wlf5.iplhq.org/isdr-icl-sendai-partnerships-2015-2025/) and, more recently, by the Kyoto 2020 Commitment for Global Promotion of Understanding and Reducing Landslide Disaster Risk KLC2020 (Sassa 2019, Sassa 2020), in particular within the priority action no. 1 "People centered early warning", and the priority action no. 3 "Technologies for monitoring, testing \& early warning".

In response to these global initiatives, natural hazard experts working with EWSs around the world have recently founded programs and networks to promote international collaboration among members engaged in both surveillance of natural hazards and issuance of warnings to key stakeholders (authorities and public). Among them we can mention multi-hazard initiatives, such as the multi-stakeholder International Network for Multi-Hazard Early Warning Systems promoted by the World Meteorological Organization (https://www.wmo.int/pages/prog/drr/documents/IN-MHEWS/IN-MHEWS.html), as well as initiatives focusing on single natural hazards, such as the Intergovernmental Oceanographic Commission Tsunami Programme (http://www.ioc-tsunami.org/), the World Organization of Volcanic Observatories (http://www.wovo.org/), the Global Seismographic Network of the IRIS consortium in USA (https://www.iris.edu/hq/programs/gsn), and the European Avalanche Warning Services (https://www.avalanches.org/). Filling a gap in this global scenario, and in response to the above-mentioned requests from the landslide risk scientific community, in July 2020 a multi-disciplinary international network of experts in LEWS was founded. The network is named "LandAware - the international network on Landslide Early Warning Systems" (https://www.landaware.org). 
The establishment of this network shall also be seen as a follow up initiative of two invitation-only workshops on territorial/geographical LEWSs, which were held in Oslo - Norway in 2016 (Devoli 2017) and in Perugia Italy in 2020 (Calvello et al. 2020). The main purpose of both workshops was to sustain an active exchange of knowledge, experiences, challenges and best practices among researchers and operators of municipal, regional and national LEWS in different countries across the globe. Each workshop was attended by around 40 participants from more than 10 countries (Figure 1). International experts in the fields of operative prediction of rainfall-induced landslides, meteorology, hydrology, geomorphology, engineering and risk communication gathered to share experiences and knowledge on operational systems and to discuss the need for cross-border future forums. A number of invited talks and diverse round tables allowed discussion on different issues related to LEWSs, ranging from input data to forecasting models, from operative warning models to management strategies (including stakeholder involvement and communication to citizens, residents, and authorities). At the end of the 2020 workshop, to consolidate the worldwide community of LEWS experts, the workshop organizers created a steering committee charged with the task of defining a strategy for setting up permanent international group on LEWSs. The establishment of LandAware was the final outcome of the work of this committee, which involved many online meetings as well as a continuous exchange of ideas, proposal and suggestions during a period of about five months, from February to June 2020.

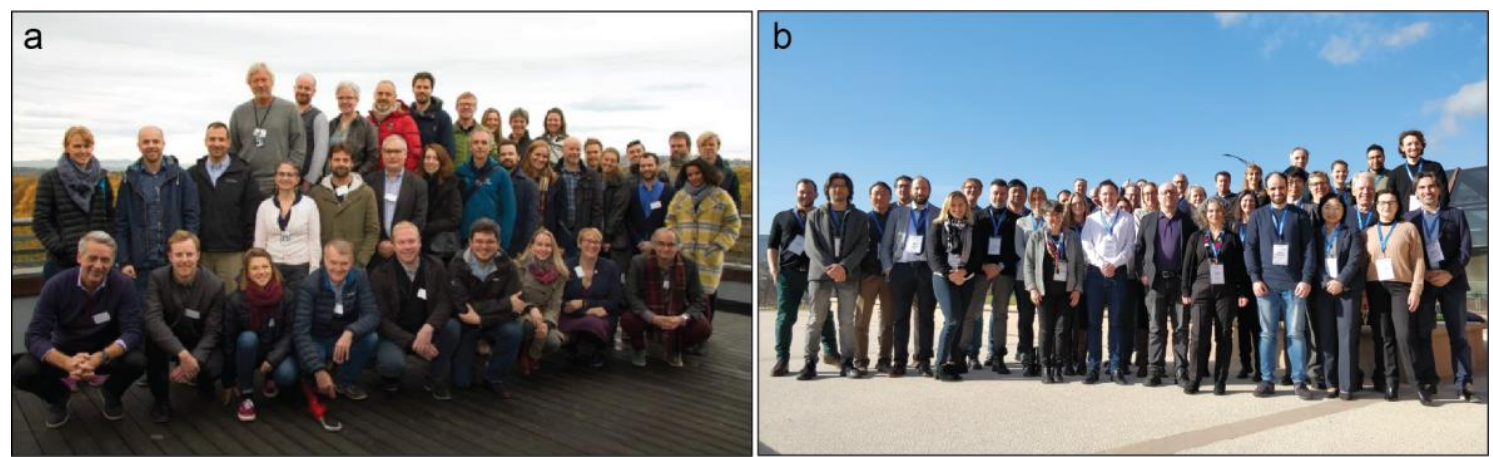

Figure 1. Group pictures of the participants to the LEWS workshops held in Oslo, Norway in 2016 (a) and in Perugia, Italy in 2020 (b)

\section{Goals and outline of the network}

LandAware shall be a multi-disciplinary, knowledge-based, non-profit network of individuals (e.g. LEWS managers, researchers, stakeholders) who are interested in cooperating for addressing and promoting practical issues related to LEWS. The primary purpose of LandAware is to share experiences, needs and innovations among LEWS professionals and researchers, and to develop and promote guidelines and best practices for upcoming LEWS. In order to achieve this, the members of LandAware are committed to:

- exchanging experiences, innovations and best practices in the development and operation of LEWS;

- promoting staff training and supporting stakeholders responsible for landslide emergency response and risk management;

- fostering cooperation between members through collaborative studies on specific cases and benchmarking of LEWS worldwide;

- enhancing the communication and awareness about landslide risk to all the categories of stakeholders;

- organizing scientific gatherings and dissemination initiatives;

- producing common standards and terminology, guidelines, recommendations, opinion papers and white papers;

- creating and maintaining online platforms as authoritative sources of information on LEWS;

- liaising with other relevant organizations that share similar objectives.

The authors of this article are the founding members of LandAware and the initial appointed members of its executive committee. The rules of LandAware are set in a cooperation agreement that was signed during a constituent general assembly held online on June 26, 2020 and entered into force on July 1, 2020. Figure 2 shows a schematic of the LandAware network. It is a bottom-up organizational structure that includes the general assembly (GA), an executive committee (EC), and a series of working groups (WGs). The network comprises two categories of membership, i.e. members and observers, committing to liaise with reliability and honesty to contribute achieving the objectives of the network. To this aim, individuals interested in cooperating for addressing and promoting issues related to LEWS can request, at any time, to become members or observers of LandAware by simply filling an online motivated request addressed to the EC (https://www.landaware.org/about/membership/). At the moment, membership does not require the payment of any annual fee. 


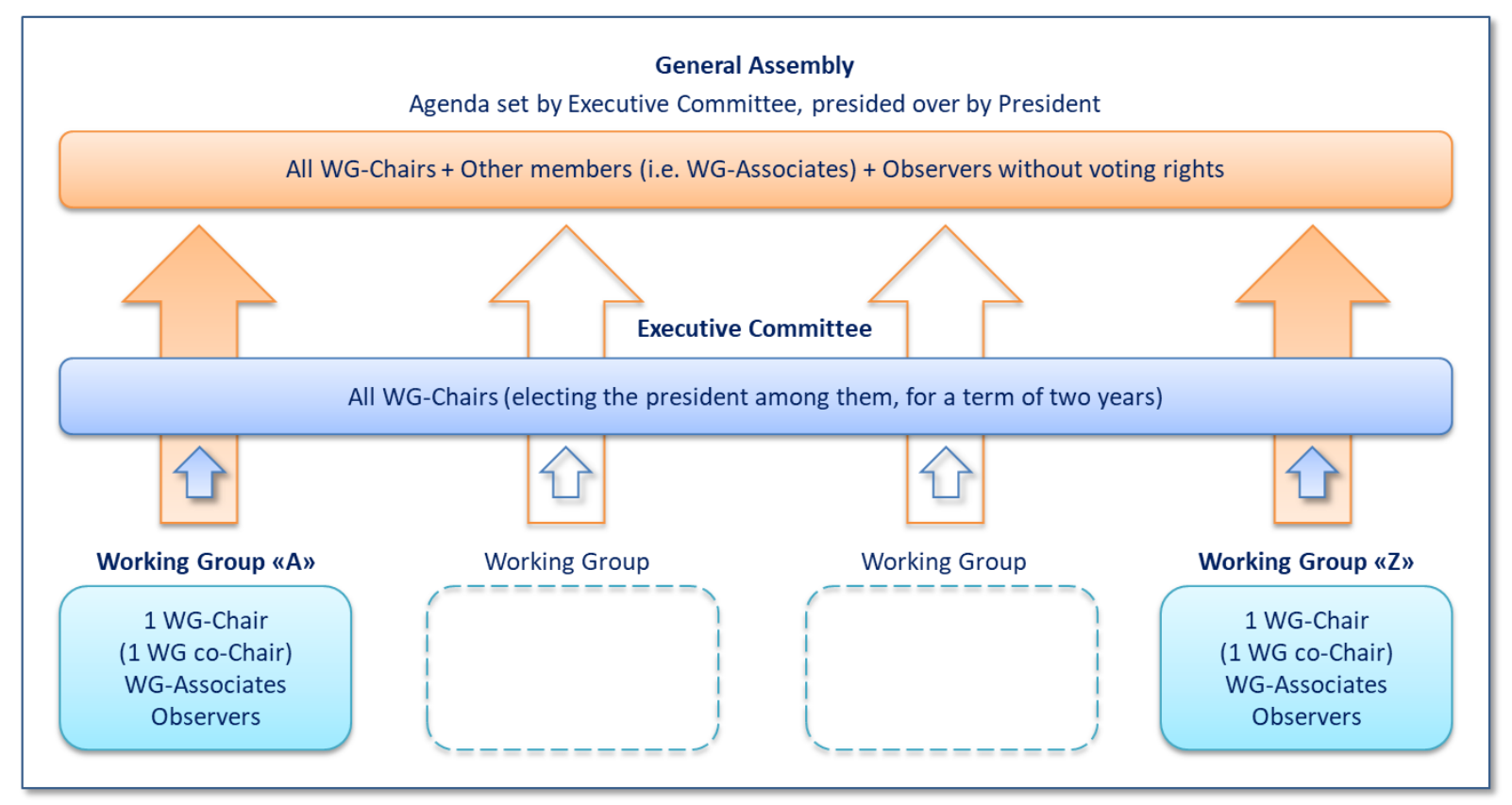

Figure 2. LandAware organizational structure

The supreme governing body of LandAware is the GA, which holds an ordinary meeting once every two years. The network's day-to-day affairs are managed by the EC, which is composed of WG-Chairs and is chaired by one of the WG-Chairs, who acts as the president of LandAware. The specific actions of the network are carried out by means of WGs, which are the main operational units of LandAware and operate on the basis of predetermined working objectives. WGs are set up with a clear mandate and operate either continuously or for a fixed period of time, in the case of working objectives that are associated to one-off deliverables. The establishment of a WG, the definition of its working objectives and the deadlines of the WG's deliverables are initially approved by the EC and then confirmed, or amended, by the GA during every ordinary meeting. Each WG is composed of one or two coordinators (WG-Chairs), members interested in the WG activities (WG-Associates) and observers.

Members are expected to participate actively in the activities of one or more active WGs during their association with LandAware. To this aim, when new members are sending a membership request to the EC, they are asked to become WG-Associates of at least one WG. Existing members and observers may request to join, or withdraw from, one or more WGs at any time during their association with LandAware. The list of LandAware's active WGs is not fixed. Indeed, it is expected to change in time in accordance to the accomplishments of established WGs, to different needs arising within the network as time goes by, and also in relation to innovative ideas coming from members engaged in the LandAware activities. New and existing members are welcome to propose to the EC new activities to perform that are fitting the general objectives of LandAware or the specific objectives of an active WG. If the establishment of a new WG is proposed, the request shall be motivated by specifying the objectives of the WG, the main forecasted activities, as well as a detailed list of deliverables for the first 2-year term of operation of the new WG.

\section{Initial and upcoming activities}

As for any new-born association, a significant part of the initial actions of LandAware was necessarily devoted to advertisement, aimed at involving as many potentially interested people as possible in the activities of the network. Advertisement included both actions tailored at specific stakeholders and more general dissemination efforts. Examples of the first category are this News/Kyoto Commitment article, which is addressed to the many scientists and practitioners regularly reading the journal "Landslides", as well as tailored messages sent via email to selected mailing lists of LEWS managers, researchers and other stakeholders. The main general purpose dissemination activity has been the creation of the LandAware web portal (https://www.landaware.org), which includes: a set of static web pages, presenting the main characteristics of LandAware; a blog section, to be used to post updates on the ongoing activities of the WGs; and a repository for deliverables and other material to be shared in open access. Other examples of the second category of actions are the creation of LandAware pages on selected social networks, such as Twitter (https://twitter.com/LandAware), Linkedln (https://www.linkedin.com/company/landaware/) and Facebook (https://www.facebook.com/LandAwareLEWS), which are intended to reach a wider audience when updating on the activities of the network.

The core activities of LandAware take place within the WGs, which are formed to discuss and address 
specific topics deemed to be of interest to the network members and, more generally, to the wider community of LEWS managers, researchers and other stakeholders. During the constituent GA and the first EC meeting, the founding members of LandAware set up the following 7 initial WGs:

1. Catalog of LEWS

2. Communication-Networking

3. Communication with stakeholders

4. eLearning

5. Innovations

6. LEWS data

7. Operational national LEWS

The aim of the WG "Catalog of LEWS" is to provide a description of the state-of-the-art of existing LEWS in form of a catalog, by describing established and operational LEWS as well as those in a final development stage. The WG "Communication-Networking" aims at communicating the main activities and advances in the network, maintaining relationships with similar networks, and organizing future meetings and workshops. The goal of the WG "Communication with stakeholders" is to promote the involvement and engagement of stakeholders, decision makers and responders in the research of LEWS. The aim of the WG "eLearning" is to promote the transfer of skills and knowledge related to various elements of LEWS by means of purposefully designed educational products to be used, over the internet, as learning experiences. The goal of the WG "Innovations" is to promote new research innovations/technologies for the use in existing or upcoming regional LEWS. The WG "LEWS data" aims to promote open data and sharing of information that can be used for landslide model development, parameterization, or evaluation. The aim of the WG "Operational national LEWS" is to promote the international collaboration among national LEWSs operational and/or in a development stage, by discussing common strengths and limitations and by providing examples of best practices and lessons learned. More details on the objectives and activities of the active WGs can be found online (https://www.landaware.org/wgs/). As already mentioned in the previous section, proposals of additional WGs to be added to the ones that are already active are strongly encouraged and can be formalized, by any LandAware member at any time, by submitting a motivated request to the EC. The EC is indeed in charge of the initial evaluation and eventual approval of new proposals, which have to be confirmed, or amended, by the GA during the following ordinary meeting.

As a final remark, it is worth commenting that the upcoming activities of LandAware will always be, given the stated purposes of the network, in line with KLC2020 priority action no. 1, which aims at promoting "the development of people-centered early warning technology for landslides with increased precision and reliable prediction both in time and location, especially in a changing climate context".

\section{References}

Calvello M (2017) Early warning strategies to cope with landslide risk. Rivista Italiana di Geotecnica 2/2017: 63-91. https://doi.org/10.19199/2017.2.0557-1405.063

Calvello M, Devoli G, Freeborough K, Gariano SL, Guzzetti F, Reeves HJ, Stähli M (2020) LEWS2020 workshop on regional Landslide Early Warning Systems - experiences, progresses and needs. EGU General Assembly 2020, EGU2020-9917. https://doi.org/10.5194/egusphere-egu2020-9917

Devoli G (2017) Workshop "Regional early warning systems for rainfall- and snowmeltinduced landslides. Need for an international forum?" summary report. 26pp. ISBN 978-82-410-1553-3. http://publikasjoner.nve.no/rapport/2017/rapport2017_04.pdf

Fathani TF, Karnawati D, Wilopo W (2016) An integrated methodology to develop a standard for landslide early warning systems. Nat Hazards Earth Syst Sci 16:2123-2135. https://doi.org/10.5194/nhess-162123-2016

Glade T, Nadim F (2014) Early warning systems for natural hazards and risks. Nat Hazards 70:1669-1671. https://doi.org/10.1007/s11069-013-1000-8

Guzzetti F, Gariano SL, Peruccacci S, Brunetti MT, Marchesini I, Rossi M, Melillo M (2020) Geographical landslide early warning systems. Earth-Sci Rev 200:102973. https://doi.org/10.1016/j.earscirev.2019.102973

Intrieri E, Gigli G, Casagli N, Nadim F (2013) Brief communication "Landslide Early Warning System: toolbox and general concepts". Nat Hazards Earth Syst Sci 13:85-90. https://doi.org/10.5194/nhess-13-85-2013

Pecoraro G, Calvello M, Piciullo L (2019). Monitoring strategies for local landslide early warning systems. Landslides, 16:213-231. https://doi.org/10.1007/s10346-018-1068-z 
Piciullo L, Calvello M, Cepeda JM (2018) Territorial early warning systems for rainfall-induced landslides. Earth-Sci Rev 179:228-247. https://doi.org/10.1016/j.earscirev.2018.02.013

Sättele M, Bründl M, Straub D (2016) Quantifying the effectiveness of early warning systems for natural hazards. Nat Hazards Earth Syst Sci 16:149-166. https://doi.org/10.5194/nhess-16-149-2016

Sassa K (2019) The Fifth World Landslide Forum and the final draft of the Kyoto 2020 Commitment. Landslides 16:201-211. https://doi.org/10.1007/s10346-018-01133-z

Sassa K (2020). Thematic issue: Sendai Landslide Partnerships 2015-2025. Landslides, online first. https://doi.org/10.1007/s10346-020-01493-5

Stähli M, Sättele M, Huggel C, McArdell BW, Lehmann P, Van Herwijnen A, Berne A, Schleiss M, Ferrari A, Kos A, Or D, Springman SM (2015) Monitoring and prediction in early warning systems for rapid mass movements. Nat Hazards Earth Syst Sci 15:905-917. https://doi.org/10.5194/nhess-15-905-2015

UNISDR - United Nations International Strategy for Disaster Reduction (2009) Terminology on Disaster Risk Reduction. http://www.unisdr.org/files/7817_UNISDRTerminologyEnglish.pdf

UNISDR - United Nations International Strategy for Disaster Reduction (2015) Sendai Framework for Disaster Risk Reduction 2015-2030. United Nations Office for Disaster Risk Reduction 37 pp 